\title{
Productivity-Adjusted Life-Years: A New Metric for Quantifying Disease Burden
}

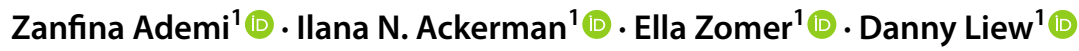

Accepted: 29 December 2020 / Published online: 11 January 2021

(c) The Author(s), under exclusive licence to Springer Nature Switzerland AG part of Springer Nature 2021

For many years, disability-adjusted life-years have been a primary focus of the landmark Global Burden of Disease studies [1]. Incorporating years of life lost and years of life lived with disability, disability-adjusted life-years provide a useful mechanism for quantifying disease burden, for any health condition and in any given country. In economic evaluations, the quality-adjusted life-year provides a complementary method of estimating the potential benefit of health interventions in terms of both quantity and quality of life [2]. In many jurisdictions, quality-adjusted life-years are used to decide whether treatments can be considered worthwhile in relation to their costs, and form the basis of decisions about the allocation of scarce healthcare resources. We propose a third measure of disease burden - the productivity-adjusted life-year (PALY).

Acute and chronic health conditions impact the work productivity of millions of people globally. A lack of investment in preventive healthcare or effective treatment options can lead to productivity loss, with broader societal and economic consequences. The work-related impacts of health conditions are often considered by assessing absenteeism (days of work missed because of a condition), presenteeism (reduced productivity while at work because of a condition) or early exit from the workforce. A number of validated tools can be used to capture work impairment, such as the Health and Labour Questionnaire [3], the Work Limitations Questionnaire [4] and the widely used Work Productivity and Activity Impairment Questionnaire [5]. These individual work impairment measures gauge productivity loss for a given study sample over a short time frame, but do not describe productivity loss at a population level nor over the working lifetime. The new PALY metric addresses this knowledge gap.

Zanfina Ademi

zanfina.ademi@monash.edu

1 School of Public Health and Preventive Medicine, Monash University, 553 St Kilda Road, Melbourne, VIC 3004, Australia
The PALY is calculated by multiplying a 'productivity index' by years lived (Fig. 1). The productivity index ranges from 0 (completely unproductive) to 1 (completely productive), and is estimated from data on time worked by fully healthy individuals, absenteeism, presenteeism and premature workforce exit. Data on absenteeism and presenteeism can be drawn from the use of the aforementioned validated tools. We commonly derive the productivity index through dividing the days worked in a year (maximum working days minus days missed because of the condition of interest) by the maximum working days in a year. The maximum working days in a year is obtained through combining information on the overall percentage of equivalent full-time workers, which is country specific and age and sex specific. For example, if the weighted average for full-time workers across the defined age range is $75 \%$, the maximum working days in a year for that particular country would be 180 days ( 240 days multiplied by 75\%). By definition, a PALY has an intrinsic economic value, and herein lies its utility. There are a number of ways to estimate this financial value. To date, we have ascribed a value to each PALY equivalent to the gross domestic product (GDP) per equivalent full-time worker for a specific country. This 'human capital' approach is simple to estimate given that GDP is an oft-reported economic metric, as are data on workforce participation. However, it is crude as GDP is generated in many ways other than people working. Another way to assign a financial value to a PALY is by using available salary estimates, which reflects both personal income for workers and income tax for governments. We recommend that PALYs only be reported as absolute values, and not be used in ratio calculations (for example, cost per PALY saved). This is because they have an inherent financial value, and hence their application to ratios will involve double counting of costs.

In the last 2 years, our group has collaboratively published PALY estimates for a range of highly prevalent health conditions and risk factors, including diabetes mellitus [6-8], coronary heart disease $[9,10]$, hypertension [11], 


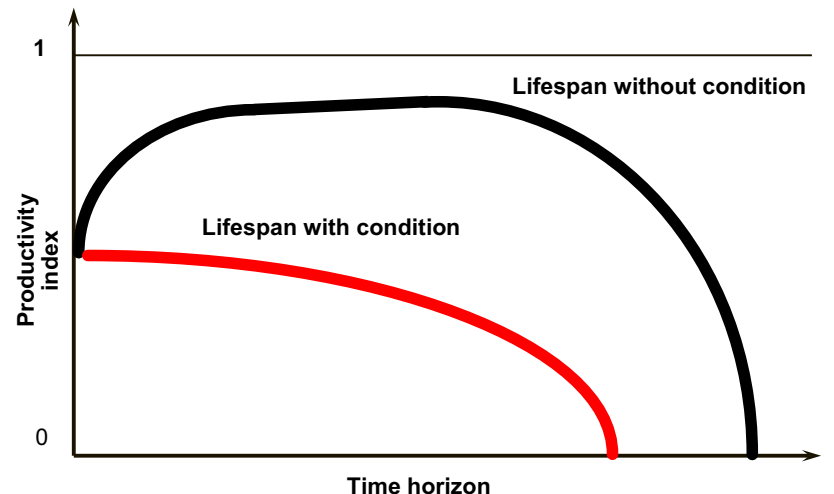

Fig. 1 Cumulative productivity-adjusted life-years over time. The difference between the two curves (representing productivity with the condition of interest in red and without the condition of interest in black) is the loss in productivity-adjusted life-years

smoking [12, 13], occupational-related hearing loss [14], pneumococcal disease [15], familial hypercholesterolaemia [16], epilepsy [17] and migraine [18]. We are now developing PALY estimates for low back pain, cancer, COVID19-related depression and acute myeloid leukaemia. As a generic measure, the PALY facilitates comparison of productivity burden across health conditions to inform practice and policy. For example, between-condition comparisons show that 1.4 and 1.0 PALYs (undiscounted) were lost per person in Australia as a result of diabetes [6] and smoking [12], respectively, over the working lifetime while 0.3 and 1.4 PALYs (discounted) were lost per person as a result of hypertension [11] and epilepsy [17], respectively. Aggregate PALY estimates can highlight not only the prevalence of a health condition and its work impacts, but also the potential for productivity gains with appropriate treatment. For example, hypertension was estimated to cause the loss of $>$ 609,000 PALYs in Australia, but optimal blood pressure control would save $>340,000$ PALYs or $\$ 76$ billion in GDP [11]. Thus far, PALY estimates have been produced for Australia [6, 9, 11, 14, 16-18], Bangladesh [8], China [7], Indonesia [10, 19], Japan, Korea [20], Malaysia [13] and Thailand [15]. Between-country comparisons of disease burden or risk factor burden can highlight significant disparities: using a consistent methodology for each country, we found that PALYs lost because of smoking totalled 15.6 million in Indonesia [19], compared with 3.0 million in Malaysia [13] and 2.5 million [12] in Australia.

We have now extensively tested and refined our PALY modelling, moving from initial 'static' life table models to 'dynamic' models that are capable of incorporating: (1) multiple health states; (2) movement of individuals in and out of the model over time; and (3) updates of prevalence, population and efficacy data. A dynamic model (accounting for future migration, births and deaths, and changes in the working age population) was most recently used to examine the impact of coronary heart disease and potential PALY gains if all new cases could be prevented over a 10-year period [9]. Importantly, we are also building researcher capacity in this new technique by training the next generation of health researchers, including those from low- and middle-income countries. Modelling support is available for researchers seeking to undertake PALY analyses within their field of interest.

Like any measure, the PALY approach has inherent limitations. By definition, PALYs focus on working age populations (usually defined as those aged 16-65 years) and productivity estimates are only simulated over the working lifetime. As health economic evaluations usually adopt a lifetime horizon, this raises a potential equity issue, particularly if PALYs are used to inform reimbursement decisions. To date, PALY models have only incorporated paid workforce data but we acknowledge that unpaid work (caregiving, child rearing, household and community roles) is also impacted by ill health. Where robust population-level data on unpaid work are available, these will enable a more complete definition of 'productivity'.

The PALY is not intended to replace the disabilityadjusted life-year or the quality-adjusted life-year. Instead, it offers a novel, but now well-tested, approach to quantifying the population-level impact of disease on productivity (arising from unemployment, days off work, reduced efficiency at work and premature death) and the broader economy. New treatments could be evaluated through estimation of the number of PALYs gained from their use. Beyond 'traditional' healthcare payers, PALYs could also be used by employers, particularly in settings where they support employee healthcare costs. For the first time, there exists an opportunity for decision making in health to be explicitly informed by the productivity burden of disease and the potential for productivity gain with effective intervention.

Author contributions ZA and INA drafted the manuscript for intellectual content. All authors provided feedback on early drafts and revised the manuscript for intellectual content.

\section{Declarations}

Funding No funding was received for the preparation of this commentary.

Conflict of interest Zanfina Ademi has no conflicts of interest that are directly relevant to the content of this article. Ilana N. Ackerman declares fellowship funds from the Victorian Government. Ella Zomer reports grant support from Amgen, AstraZeneca, Pfizer and Shire, outside the submitted work. Danny Liew declares grants from Abbvie, Amgen, AstraZeneca, Bristol-Myers Squibb, Edwards Lifesciences, Pfizer and Sanofi, and past participation in advisory boards and/or receipt of honoraria from Abbvie, Amgen, Astellas, AstraZeneca, Bris- 
tol-Myers Squibb, Edwards Lifesciences, Novartis, Pfizer, Sanofi and Shire, outside the submitted work.

Ethics approval Not applicable.

Consent to participate Not applicable.

Consent for publication Not applicable.

Availability of data and material Not applicable.

Code availability Not applicable.

\section{References}

1. Vos T, Lim SS, Abbafati C, et al. Global burden of 369 diseases and injuries in 204 countries and territories, 1990-2019: a systematic analysis for the Global Burden of Disease Study 2019. Lancet. 2020;396:1204-22.

2. Whitehead SJ, Ali S. Health outcomes in economic evaluation: the QALY and utilities. Br Med Bull. 2010;96:5-21.

3. Van Roijen L, Essink-bot M-L, Koopmanschap MA, Bonsel G, Rutten FFH. Labor and health status in economic evaluation of health care: the Health and Labor Questionnaire. Int J Technol Assess Health Care. 1996;12:405-15.

4. Lerner D, Amick BC, Rogers WH, Malspeis S, Bungay K, Cynn D. The Work Limitations Questionnaire. Med Care. 2001;39:72-85.

5. Reilly MC, Zbrozek AS, Dukes EM. The validity and reproducibility of a work productivity and activity impairment instrument. Pharmacoeconomics. 1993;4:353-65.

6. Magliano DJ, Martin VJ, Owen AJ, Zomer E, Liew D. The productivity burden of diabetes at a population level. Diabetes Care. 2018;41:979-84.

7. Hird TR, Zomer E, Owen A, et al. The impact of diabetes on productivity in China. Diabetologia. 2019;62:1195-203.

8. Afroz A, Hird TR, Zomer E, et al. The impact of diabetes on the productivity and economy of Bangladesh. BMJ Glob Health. 2020;5:e02420.
9. Savira F, Wang BH, Kompa AR, et al. The impact of coronary heart disease prevention on work productivity: a 10-year analysis. Eur J Prev Cardiol. 2020. https://doi.org/10.1093/eurjpc/zwaa037 ((Epub ahead of print)).

10. Uli RE, Satyana RPU, Zomer E, Magliano D, Liew D, Ademi Z. Health and productivity burden of coronary heart disease in the working Indonesian population using life-table modelling. BMJ Open. 2020;10:e039221.

11. Hird TR, Zomer E, Owen AJ, Magliano DJ, Liew D, Ademi Z. Productivity burden of hypertension in Australia. Hypertension. 2019;73:777-84.

12. Owen AJ, Maulida SB, Zomer E, Liew D. Productivity burden of smoking in Australia: a life table modelling study. Tob Control. 2019;28:297-304.

13. Tan QY, Zomer E, Owen AJ, Chin KL, Liew D. Impact of tobacco use on health and work productivity in Malaysia. Tob Control. 2020;29:111-7.

14. Si S, Lewkowski K, Fritschi L, Heyworth J, Liew D, Li I. Productivity burden of occupational noise-induced hearing loss in Australia: a life table modelling study. Int J Environ Res Public Health. 2020;17:4667.

15. Ounsirithupsakul T, Dilokthornsakul P, Kongpakwattana K, Ademi Z, Liew D, Chaiyakunapruk N. Estimating the productivity burden of pediatric pneumococcal disease in Thailand. Appl Health Econ Health Policy. 2020;18:579-87.

16. Ademi Z, Marquina C, Zomer E, et al. The economic impact of familial hypercholesterolemia on productivity. J Clin Lipidol. 2020. https://doi.org/10.1016/j.jacl.2020.08.004 ((Epub ahead of print)).

17. Foster E, Chen Z, Zomer E, et al. The costs of epilepsy in Australia: a productivity-based analysis. Neurology. 2020. https://doi. org/10.1212/WNL.0000000000010862 ((Epub ahead of print)).

18. Tu S, Liew D, Ademi Z, Owen AJ, Zomer E. The health and productivity burden of migraines in Australia. Headache. 2020. https://doi.org/10.1111/head.13969 ((Epub ahead of print)).

19. Satyana R, Uli R, Magliano D, Zomer E, Liew D, Ademi Z. PNS16 Health and economic burden of smoking in Indonesia. Value Health Reg Issues. 2020;22:S83.

20. Zomer E, Rhee Y, Liew D, Ademi Z. PMH2 The impact of major depression on productivity in South Korea. Value Health Reg Issues. 2020;22:S61. 